\title{
Cosmopolitan De-scriptions: Shanghai and Hong Kong
}

\author{
Ackbar Abbas
}

"I like all big cities. More than Japanese, I feel I'm from Tokyo, where I was born. . . Tokyo has no nationality." Yohji Yamamoto, in Wim Wenders's 1989 film Notebook on Cities and Clothes

O ne of the most moving, and revealing, texts of the Argentinian writer Jorge Luis Borges is his short 1954 preface to A Universal History of Infamy, a collection of stories first published in 1935. During the two decades between the original publication and the 1954 preface, Borges had established himself as a cosmopolitan writer who belonged not just to Argentina but to the world. However, it is possible to see Borges's cosmopolitanism both as the great cultural achievement that it unquestionably and as a response to a quasi-colonial situation that inevitably leaves its traces, however indirectly. In Borges, we find these traces in the excessive and exhaustive erudition that he is famous for and that he calls the baroque: "I would define as baroque the style that deliberately exhausts (or tries to exhaust) its own possibilities, and that borders on selfcaricature."' That there is some relation between style and situation, between the baroque and the colonial, becomes clear when we learn a little later in the same

I wish to thank Mario Gandelsonas, Benjamin Lee, Jeremy Tambling, and the editors of Public Culture for their helpful comments during various stages of completion of this essay.

1. All quotations are from the preface in Jorge Luis Borges, Collected Fictions, trans. Andrew Hurley (New York: Viking, 1998), 4-5.

Public Culture 12(3): 769-786

Copyright (C) 2000 by Duke University Press 
preface that Borges's baroque originated as "the sport of a shy sort of man who could not bring himself to write short stories, and so amused himself by changing and distorting (sometimes without aesthetic justification) the stories of other men." In a colonial or quasi-colonial situation, even our "own" stories have to begin as "stories of other men." No wonder that it was some time before Borges could turn from "these ambiguous exercises" to "the arduous composition of a straightforward short story —-Man on Pink Corner'...."

Besides being a mask for shyness, there is another, less attractive, side to Borges's erudition: it can be related to a tendency toward displays of knowledge or knowingness that comes from the colonial's anxiety to be recognised. This is perhaps what the Spanish director Luis Buñuel intuited in the Argentinian writer, without quite understanding its provenance. Buñuel mentions Borges in some cutting remarks in his autobiography My Last Sigh: "Just because someone writes well doesn't mean you have to like him.... he struck me as very pretentious and self-absorbed. There's something too academic (or as we say in Spanish, sienta cátedra) about everything he says, something exhibitionistic. Like many blind people, he's an eloquent speaker, albeit the subject of the Nobel Prize tends to crop up excessively each time he talks to reporters."2 (This is a tendency, we might add, to which many Chinese aspirants to the prize are also prone.) Buñuel's cruel way of snubbing Borges is simply to remark in parentheses "as we say in Spanish," a we that shoulders Borges back onto the margins; as if the metropolitan and the colonial were clearly divided by a common language. For all Borges's aloofness or air of detachment (as when he writes in his essay "The Argentine Writer and Tradition": "I believe our tradition is all of Western culture. . . our patrimony is the universe; we should essay all themes, and we cannot limit ourselves to purely Argentine subjects in order to be Argentine"3) a certain shrillness is discernable - at least to a European like Buñuel-in his advocacy of a cosmopolitan stance.

I begin with this encounter between Borges and Buñuel because it illustrates some of the ambiguities of the cosmopolitan. In Borges's case, cosmopolitanism was, first, a modernist argument against the tyranny of "tradition" as narrow parochialisms and ethnocentrism: this was the critical aspect of his cultural universalism ("our patrimony is the universe") — in much the same way that the

2. Luis Buñuel, My Last Sigh, trans. Abigail Israel (New York: Vintage, 1984), 221.

3. Borges, Labyrinths, ed. Donald A. Yates and James E. Irby (New York: New Directions, 1964), 184. 
universalism of "structure" was to Claude Lèvi-Strauss a critical safeguard against ethnocentric bias. ${ }^{4}$ The problem begins when this universalism is identified with Western culture ("I believe our tradition is all of Western culture ..."). This identification did not happen by chance. In the modern era, which corresponded to the economic and political dominance of Western nations, cosmopolitanism by and large meant being versed in Western ways, and the vision of "one world" culture was only a sometimes unconscious, sometimes unconscionable, euphemism for "First World" culture.

This relationship of cosmopolitanism to power suggests that it cannot be thought of simply as an honorific or a universalist term, connoting either an ability to transcend narrow loyalties and ethnocentric prejudices or a sympathetic disposition to "the other." The ideal of cosmopolitanism, to quote a muchdiscussed essay of Ulf Hannerz's, as “an orientation, a willingness to engage with the Other . . . an intellectual and aesthetic stance of openness toward divergent cultural experiences" 5 may be an admirable one, but it is sustainable only in metropolitan centers where movement and travel are undertaken with ease and where the encounter with other cultures is a matter of free choice, negotiated on favourable terms. But what about a situation where these conditions are not available - a situation where "divergent cultural experiences" are not freely chosen but forced on us, as they are under colonialism? What form of "openness" should we cultivate then, and would this constitute a cosmopolitan stance or a compradorist one? Could cosmopolitanism be one version of "cultural imperialism"? Is there a chapter missing in Borges's A Universal History of Infamy, a chapter on colonialism as infamy?

These questions need to be asked, but to answer them by equating cosmopolitanism with cultural imperialism is ultimately as simplistic as it is to see it in purely celebratory terms. If we take the position I have been pursuing - that to understand cosmopolitanism and its valences, we will have to take account of the historical conditions under which it arises - then we will need to turn from Borges's time to our own and to consider the question of globalism. Globalism is the historical condition of our time, but it also raises new questions and threatens to make old ones redundant. Thus, the information technologies often associated with globalism promise to make parochialism, and hence the urgency of its critique, a thing of the past. At the same time, these technologies have been accom-

4. See, for example, the final chapters of Claude Lèvi-Strauss, Tristes Tropiques, trans. John and Doreen Weightman (New York: Atheneum, 1974).

5. Ulf Hannerz, "Cosmopolitans and Locals in World Culture," in Global Culture, ed. Mike Featherstone (London: Sage, 1990), 239. 
panied by such radical mutations in economic and political space (variously theorised as "post-Fordism," "disorganized capitalism," "the risk society," and "the network society") that "imperialism" in the classical sense as the clear-cut exploitation of one nation-state by another is becoming almost unrecognisable. ${ }^{6}$ How can we describe cosmopolitanism under these changed conditions?

Instead of approaching such a question theoretically, I look again at the cosmopolitan through the history of two Asian cities, Shanghai and Hong Kong, and the urban cultures they developed. Cities have historically been the privileged, if not necessarily exclusive, sites for the emergence of the form of life that we call the cosmopolitan. In Shanghai and Hong Kong, in particular, some form of the cosmopolitan did indeed emerge under colonial conditions, and some other form of cosmopolitanism may be developing today. Nevertheless, the description of Shanghai and Hong Kong I give here is not intended to be a straightforward empirical account of what kind of cosmopolitan city each became under colonial rule or what crucial changes each is undergoing as communist China today reasserts itself as a global power. Rather, I direct attention to a certain elusive quality of both cities and to the fact that the most familiar images of these cities do not necessarily describe them best. To put this another way: cosmopolitanism must take place somewhere, in specific sites and situations - even if these places are more and more beginning to resemble those "non-places" that French anthropologist Marc Augé has argued characterise the contemporary city. In a non-place, "one is neither chez soi nor chez les autres." Like the city, Augé's non-place must be understood not literally, but as paradox: a non-place is far from being nonexistent. Rather, it is a result of excess and overcomplexity, of a limit having been exceeded. Beyond a certain point, there is a blurring and scrambling of signs and an overlapping of spatial and temporal grids, all of which make urban signs and images difficult to read. The overcomplex space of non-places means, among other things, that even the anomalous detail may no longer be recognisable as such because it coexists with a swarm of other such details. This means the anomalous is in danger of turning nondescript, in much the same way that the more complex the city today, the more it becomes a city without qualities. The cosmopolitan as urban phenomenon is inevitably inscribed in such non-

6. See, for example, David Harvey, The Condition of Postmodernity (Oxford: Blackwell, 1989); Scott Lash and John Urry, The End of Organized Capitalism (Cambridge: Polity Press, 1987); Ulrich Beck, Risk Society (London: Sage, 1992); and Manuel Castells, The Rise of the Network Society (Oxford: Blackwell, 1996).

7. Marc Augé, A Sense for the Other, trans. Amy Jacobs (Stanford, Calif.: Stanford University Press, 1998), 106. 
places and paradoxes, raising the question we will have to address at some later point of how it might survive there.

To grapple with the anomalous/nondescript nature of overcomplex spaces, I draw on what Ludwig Wittgenstein called "description" and appropriate it for the analysis of cities. ${ }^{8}$ On the one hand, when Wittgenstein writes that "we must do away with all explanation, and description alone must take its place," description can be understood as a kind of de-scription. This means that it is concerned not with knitting together explanations that make smooth connections between disparate series; rather, it welcomes friction - that is, disjuncture - and the mobile, fugitive, fragmentary detail. Wittgenstein writes: "We want to walk: so we need friction. Back to the rough ground!" On the other hand, Wittgenstein also insists that what concerns description is "of course, not empirical problems": "And this description gets its light, that is to say its purpose, from the philosophical problems. These are, of course, not empirical problems; they are solved, rather, by looking into the workings of our language, and that in such a way as to make us recognize those workings: in despite of an urge to misunderstand them." For our purposes, what might correspond to "language" is space. As philosophical issues are resolved by looking into the workings of language, so urban issues like cosmopolitanism might be clarified through a critique of space. Like language, space produces "an urge to misunderstand" its workings, an urge that needs to be resisted through de-scription.

What follows, then, is neither a theoretical nor an empirical account, but a de-scription of the cosmopolitan in relation to the spatial history of Shanghai and Hong Kong.

Shanghai and Hong Kong have always had a special relation to each other, if only through their relationship to the rest of the world. The historical facts about them are well known. Both cities were essentially created by Western colonialism in the aftermath of the Opium Wars: Shanghai as a lucrative treaty port and Hong Kong as a British colony and staging post for trade with China. For better or for worse, the two cities seemed to have been linked at birth, which makes it possible sometimes to read what is tacit in the history of one city in the history of the other. Each developed a form of cosmopolitanism under colonialism. From the outset, Shanghai generated a set of images about itself that contributed to its

8. All quotations are from paragraphs 107 and 109 of Ludwig Wittgenstein, Philosophical Investigations, trans. G. E. M. Anscombe (Oxford: Basil Blackwell, 1974), 46-47. 
mystique but that we sometimes think of as merely outlandish or bizarre. Nevertheless, it is these often conflicting and contradictory images that we will need to interrogate. It may be that every city gives itself away in the self-images that it produces; somewhat like dream images that lead us to another history, or like cinema where, as Gilles Deleuze has argued, it is the filmic image that underlies the film narrative and not the other way around. ${ }^{9}$

We can begin with Shanghai, which was historically the senior city. Consider the political anomaly of extraterritoriality. In Shanghai, within the space of a hundred years, the extraterritorial presence of foreigners-British, American, and French, and, after 1895, Japanese (to name only the most obvious) - turned the city into the Shanghai of legend, into what J. G. Ballard called "this electric and lurid city more exciting than any other in the world." 10 The existence of the different concessions, each with its own set of extraterritorial laws, meant that internal control of the city always had to be negotiated, often with the triad underworld operating as unofficial arbiters. However, this created less an anarchic city than a polycentric, decentered city controlled by many different hands. For example, the French Settlement used a 110-volt electric system, while the International Settlement used 220 volts! But far from being lawless, the space of Shanghai was subject to constant negotiations, and every initiative was observed from multiple perspectives. It was the existence of such a negotiated space that helped Shanghai in the 1920s and 1930s develop its own special brand of cosmopolitan urban culture: what we might call a cosmopolitanism of extraterritoriality.

The most visible signature of extraterritoriality was in the city's built space, with its proliferation of different styles of architecture, by turns elegant and kitschy. There were Tudor-style villas, Spanish-style townhouses, Russian-style churches, and German-style mansions, along with the internationalism of the buildings on the Bund and, of course, the Shanghainese lanehouses or Li Long housing complexes, these last also built by foreign architects with their preconceptions of what vernacular housing should look like. It was all a question of style imported from elsewhere - a shallow kind of cosmopolitanism, a dream image of Europe more glamorous even than Europe itself at the time; the whole testifying, it seems, to the domination of the foreign, especially if we remember the decrepitude of the Chinese section of the city. But, at least in part, this was a deceptive testimony because within this setting something contrary was also

9. See Gilles Deleuze, Cinema, 2 vols., trans. Hugh Tomlinson and Barbara Habberjam (Minneapolis: University of Minnesota Press, 1986-89).

10. J. G. Ballard, Empire of the Sun (London: Grafton Books, 1985), 17. 
happening. It could be argued, as Leo Ou-fan Lee has done in "Shanghai Modern," that the foreign presence produced not only new kinds of public and social spaces (such as cinemas, department stores, coffeehouses, dance halls, parks, and racecourses), but also spaces that could be appropriated by the Chinese themselves and used to construct a Chinese version of modern cosmopolitan culture. From this point of view, cosmopolitanism in Shanghai could be understood not as the cultural domination by the foreign but as the appropriation by the local of "elements of foreign culture to enrich a new national culture."11 Lee's persuasive account, rich in fascinating details, is interesting, too, for its attempt to steer the argument away from too facile "political critiques" of the cosmopolitan as cultural imperialism, towards a more nuanced reading of cultural history.

Still, foreign domination and local appropriation are not necessarily mutually exclusive. For example, it should not be forgotten that Shanghai's strength as a cosmopolitan city was always based on China's weakness as a nation. As such, there was always an underlying tension between national culture on the one hand, which could only be constructed as anticolonial resistance, and Shanghai cosmopolitanism on the other. Shanghai was always a subtly nonviable city, where splendour and squalor existed side by side. It was precisely the city's characteristic multivalence - its capacity to be all at once a space of negotiation, domination, and appropriation - that generated yet another image, perhaps the most telling of all: the grotesque. This grotesque nature of the city is captured best in a scene in Ballard's semiautobiographical novel, Empire of the Sun, documenting the last days of old Shanghai. The scene is set outside the Cathay Theater, at the time the largest cinema in the world. For its showing of The Hunchback of Notre Dame, the management recruited two hundred real-life hunchbacks from the back streets of Shanghai to form an "honour guard" for the glitterati attending the show! A grand guignol quality was never far behind the cosmopolitanism of Shanghai.

This grotesque element hints at something quite significant about Shanghai's cosmopolitanism, which could be extended even to the cosmopolitanism of other cities. It suggests that the cosmopolitan "attitude" in this case consists not in the toleration of difference but in the necessary cultivation of indifference: the hunchbacks were hired not in the spirit of equal opportunity employment but to create a gross sensation. Furthermore, to some extent the colonial experience had shattered the innocence of difference. The end result of having to negotiate a

11. Leo Ou-fan Lee, "Shanghai Modern: Reflections on Urban Culture in China in the 1930s," Public Culture 11 (1999): 104. 
multivalent space that makes so many contrary demands on the individual was the cultivation of indifference and insensitivity to others. Even scandal and outrage could be openly accepted. Indeed, in its time old Shanghai had the reputation of being the most "open" city in the world. It was the one place in China that was free from the control of a debilitated and bureaucratic state apparatus, giving it an air of freedom that drew in both political reformers and intellectuals, both prostitutes and adventurers. The other side of this freedom and openness, however, was a certain isolation - a linkage to the world that went together with a delinkage from the rest of China. There was always something very fragile about Shanghai cosmopolitanism. After 1949, Chinese communism, born in Shanghai, quickly made Shanghai's urban culture no more than a memory.

It took Mao Zedong's genius to see, against the grain of orthodox Marxism, that even rural spaces, at least in the historical situation of China, had a crucial role to play in modern and national life. This was the insight that allowed Mao to displace cities in general from their role as the sole exclusive site of modernity - and Shanghai in particular from its claim to be China's preeminent city. After 1949, the city could no longer enjoy the privilege of being a law unto itself: it was clearly the nation that now held sway over the city. During these years, Shanghai did tacit penance for its past Babylonian ways. It remained a center of industrial production, but only to help finance the modernization of the rest of the country; however, it was forced to discard its cosmopolitan cultural life that Maoist puritanism regarded as bourgeois and decadent. And as China moved into the phase of national rebuilding under communism, the conditions for the emergence of a different kind of cosmopolitan space moved elsewhere - to the British crown colony of Hong Kong.

The story is often told that it was an act of emigration, the flight of twenty-one Shanghai industrialist families to Hong Kong with their capital and business expertise, that formed the basis of Hong Kong's industrial development from the 1950s onwards. In chronological terms, the rise of Hong Kong indeed succeeded the fall of Shanghai. The injection of capital and human resources to the colony that followed was certainly one factor in its growth as an international city, but it was not the only or even necessarily the most important factor. What was equally decisive, paradoxical as this may sound, was Hong Kong's dependent position and the way it made a career of dependency. ${ }^{12}$ In Shanghai even at its most

12. I have written at greater length on Hong Kong and the paradoxical meaning of dependency elsewhere. See, for example, Ackbar Abbas, Hong Kong: Culture and the Politics of Disappearance (Minneapolis: University of Minnesota Press, 1997). 
corrupt, there was always some vestigial interest in issues of nationalism as a means of liberation and independence. For example, it is well known that even notorious triad societies like the Green Gang, when not engaged in nefarious activity, had nationalist concerns - and both Sun Yatsen and Chiang Kaishek drew on them for help. In Hong Kong, by contrast, there was no possibility of and hence little interest in — nationalism. Hong Kong could never have been a city nation like Singapore, only a hyphenation. It therefore accepted its colonial status as a priori and turned towards the international, fully exploiting its position as a port city or, in Mao's picturesque phraseology, as a pimple on the backside of China. Hong Kong was less a site than a para-site. If colonialism in Hong Kong had a certain benign-looking aspect to it, it was because it was a mutant political entity and a living demonstration of how the relative autonomy that comes from economic success could be based on dependency. While Shanghai was multiple and polyvalent, Hong Kong was single and paradoxical.

For a long time, Hong Kong did not develop the kind of cosmopolitan culture that Shanghai exhibited in the 1920s and 1930s, a cosmopolitanism that emerged from the anomalous space of extraterritoriality. Dependency meant that for most of its history, Hong Kong, culturally speaking, was caught in the double bind of divided loyalties. It was politically ambivalent about both Britain and China; ambivalent about what language, English or Chinese, it should master; and confident only about capital. The one moment when it began to rival the cultural vibrancy of Shanghai in the 1930s was during the 1980s and 1990s, after the Joint Declaration announcing the return of Hong Kong to China in 1997: that is, at precisely the moment when Hong Kong felt most vulnerable and dependent. This was the period when more and more people discovered, invented, and rallied behind what they called "Hong Kong culture." This Hong Kong culture was a hothouse plant that appeared at the moment when something was disappearing: a case of love at last sight, a culture of disappearance. In contrast to Shanghai in the 1930s, nationalism was a negative stimulus: one major anxiety was that the internationalism of the port city would be submerged and smothered by its reinscription into the nation. But the anxiety was tempered by a tacit hope that Hong Kong might indeed be a special case. This was what redirected attention back to the city's local peculiarities, in an attempt to reinvent it one last time even as it disappeared. This sense of disappearance as the experience of living through the best and the worst of times was the seminal theme of the New Hong Kong Cinema. If filmmakers like Wong Kar-wai, Stanley Kwan, Ann Hui, and Tsui Hark managed to convey in their films a cosmopolitan sensibility, it was partly by focusing on local issues and settings, but in such a way that the local was 
dislocated: through the construction of innovative film images and narratives and, above all, through the introduction of the disappearing city as a major protagonist in their films. ${ }^{13}$ Hong Kong cosmopolitanism was stimulated then not so much by a space of multivalence - which was the case in 1930s Shanghai-as by a space of disappearance, one effect of which was the transformation of the local into the translocal as a result of historical exigencies.

To recapitulate: in Shanghai in the 1920s and 1930s we found a cosmopolitanism of extraterritoriality, and in Hong Kong from the 1980s onward, a cosmopolitanism of dependency, with its thematic of the disappearing city. But what of today and tomorrow? Two events in the 1990s can be considered symptoms that the cultural space these two cities seem destined to cohabit is once again changing. The 1990s saw not only the return of Hong Kong to China as an SAR (Special Administrative Region) but also the economic and cultural reappearance of Shanghai after more than four decades in the political cold. To consider if a new kind of cosmopolitanism is emerging today in Shanghai and Hong Kong, we will first have to consider the changing historical space of these two cities.

Now that Hong Kong is part of China again, there is a lot of speculation about whether Shanghai will replace it as the country's main economic and financial center once the Chinese yuan becomes fully convertible. The mayor of Shanghai, Xu Kuangdi, in a Hong Kong newspaper interview, addressed the issue of Shanghai and Hong Kong as follows: "You don't have to worry about Shanghai replacing Hong Kong; or that because of Hong Kong, Shanghai is not going to become a financial centre. They play different roles... . In the future, their relationship will be like two good forwards on a football team. They will pass the ball to each other and both will do their best to score more goals. But they are on the same team-China's national team." In the same interview, he conceded that Hong Kong "is more international than Shanghai. It is a financial centre for Southeast Asia. Not only does it link China with the world, it also serves as a trading market for Southeast Asian countries. Shanghai primarily serves as a link between the mainland and the rest of the world." 14

Xu's homely image of Shanghai and Hong Kong as two good forwards on the national team is reassuring because as a public statement it understandably

13. See Abbas, "The Erotics of Disappointment," in Wong Kar-wai, ed. Jean-Marc Lalanne, David Martinez, Ackbar Abbas, and Jimmy Ngai (Paris: Editions Dis Voir, 1997), 39-81.

14. Xu Kuangdi, interview by Matthew Miller and Foo Choy Peng, South China Morning Post (Hong Kong), China Business Review section, 9 July 1998, 8. 
minimises whatever tensions might exist between the city, the nation, and the transnational or global. But such tensions do exist. In Hong Kong, for example, these tensions produced a skewing of cultural and political space that could be read in the city's cultural forms, such as its architecture and new cinema. The return of Hong Kong to China threatened to make the former disappear in the sense that the transnational status it had established for itself might be merged and submerged into the national. In Shanghai, because of the different relation of the city to the nation, it is not a question of the city's disappearance but of its reappearance, a reappearance coinciding with China's reinscription, after decades of closure, into the global economy. But Shanghai's "reappearance" is as complexly situated as Hong Kong's culture of disappearance in a space of tensions and skewed images. For example, since the early 1990s Shanghai has been obsessed with a mania for building and urban development, but accompanying it like a shadow is something that at first sight seems rather puzzling: the state's interest in preservation projects. It is within the problematic of tensions between the city, the nation, and the transnational that comparisons between "reappearance" in Shanghai and "disappearance" in Hong Kong can be made and the question of cosmopolitanism can be posed.

Let's take the Shanghai case. Before the early 1990s, there was very little interest among the Shanghainese in the buildings they lived and worked in. If a large part of old Shanghai was preserved, it was by default, because the city had too few resources to embark on major programs of urban restructuring. As late as the early 1990s, visitors to Shanghai often remarked how little Shanghai had changed visually from its pre-1949 days, except to note that a large part of the glitter had gone. However, after Deng Xiaoping's 1992 visit, and within the space of a few years, the Pudong area of Shanghai across the Huangpu River from the Bund has developed into a mini-Manhattan, following Deng's agenda for it: "A new look each year, a transformation in three years." Today, even Hong Kong visitors, blasé about new buildings, are amazed by Shanghai. In a few short years, Shanghai saw the construction of over a thousand skyscrapers, a subway line, a highway overpass ringing the city, another bridge and tunnel across the Huangpu to Pudong, and the urbanization of Pudong itself, now coming into being before our eyes like the speeded-up image of time-lapse film. Interestingly enough, together with this frenzy of building and development - subsidised by the sale of land leases and joint venture capital - the city has shown an interest in preservation, something not specifically recommended by Deng. So far, around 250 buildings have been registered as municipal listed buildings, with another 200 more being considered. This is remarkable enough for us to ask, What, in fact, is happening? 
Let me offer the following hypothesis: Preservation in Shanghai is motivated by something quite different from the usual pieties about "cultural heritage," which, given the city's colonial past, can only be ambiguous. It is motivated more by anticipations of a new Shanghai to rival the old than simply by nostalgia for the past. In other words, preservation is something more complex than just a question of the past remembered: in Shanghai, the past allows the present to pursue the future; hence "memory" itself is select and fissured, sometimes indistinguishable from amnesia. This paradox of the past as the future's future also throws a particular light on Shanghai's urban development, which, like preservation, takes on a special quality: Shanghai today is not just a city on the make with the new and brash everywhere - as might be said more aptly of Shenzhen, for example. It is also something more subtle and historically elusive: the city as remake, a shot-by-shot reworking of a classic, with the latest technology, a different cast, and a new audience. Not "Back to the Future" but "Forward to the Past." The minor story of preservation in Shanghai gives an important gloss - in both senses of the word - to the major story of urban development.

In rapidly developing cities, urban preservation as a rule is either ignored or merely paid lip service. Take the case of Hong Kong, in many ways a role model for Shanghai and other Chinese cities. Yet Hong Kong offers a comparatively straightforward example of the relationship between development and preservation. Though it is true that there are some preserved buildings in this former British colony - the best known being the clock tower of the demolished Hong Kong-Canton Railway Station, now a part of the Hong Kong Cultural Centre Complex; the old Supreme Court building; Western Market; and Flagstaff House, formerly British military headquarters and now a tea museum-on the whole, preservation happens ad hoc, with no systematic plan for municipal preservation comparable to Shanghai's. An interest in Hong Kong and its history, moreover, and hence in preservation, is only a recent phenomenon with origins tied to 1997 and an anxiety that Hong Kong as we knew it might come to an end with the handover. However, such an interest in preservation never proved strong enough to prevent hard-nosed development decisions from being made in the market economy of a so-called noninterventionist state, and this circumstance has changed little since Hong Kong became an SAR. By contrast, the twist that Shanghai provides is in opting to develop and, at the same time, preserve at least part of the city, as if deliberately giving the lie to the notion that development and preservation are incompatible. This presents us with enough of an anomaly to prompt the question: Precisely what role is preservation meant to play in Shanghai's impending transformation? 
To begin with the obvious, the economic importance of preservation cannot be underestimated. Invoking a continuity with a legendary past - no matter how ambiguous that past may have been-enhances the city's attractiveness, gives it historical cachet, and hence equips it to compete for foreign investment and the tourist trade on more favourable terms. The past is a kind of symbolic capital. At the same time, preservation often accompanies the revitalization and gentrification of decaying areas of the city and contributes to urban renewal. But preservation has a third feature peculiar to Shanghai itself: namely, the way the economic role of preservation maps onto the tensions inherent in China's "socialist market economy." Since late 1978, this economy has created a private sector within a socialist state; that is, it has allowed the global into the national. Moreover, the new private sector has consistently outperformed the state in the marketplace, raising questions of to what degree the state is in touch with the new market conditions. Mao had succeeded in curtailing capitalism by establishing the socialist state, just as Europe had ameliorated capitalism's effects through the welfaredemocratic state. But that was a bygone capitalism. The new capitalism, global capital, is freshly able to act, constantly outpacing the interventions of the nationstate and making it look heavy-footed. ${ }^{15}$

In this context, the state's interest in preservation, via municipal policy, makes a lot of sense. Not only is preservation well within the competence of the state; it is also a way by which the state can enter the global market through promoting the city's past - that is, through the heritage industry. It is an implicit assertion of the state's involvement in and contribution to the future development of Shanghai-a way of mediating the need of the state for legitimacy and the demand of the private sector for profitability. By a strange twist, the state's interest in preservation is an assertion that it is still a player in the new global game. Hence, the entirely different relation to preservation in Hong Kong and Shanghai: in the one, ad hoc and linked to anxieties about the city's disappearance; in the other, state-planned and related to the city's reappearance as a soi-disant "City of Culture."

The working together of development and preservation in Shanghai suggests that a new problematic is emerging. Something peculiar must be happening if preservation produces not a sense of history but the virtuality of a present that has erased the distinction between old and new - or where local history is another gambit in the game of global capital. Perhaps virtual cities can only look like

15. On these issues, see Ulrich Beck, What Is Globalization? (Cambridge: Polity Press, 2000). 
what Shanghai today looks like, with old and new compressed together in an apocalyptic now. The listed buildings on the Bund and the chaos of skyscrapers in Pudong do not so much confront as complement each other on either side of the Huangpu River; in a sense, both old and new are simply steps in the remake of Shanghai as a City of Culture in the new global space. In such a space, heritage issues can be fused and confused with political and economic interests. And precisely because of this, urban preservation in the global era cannot be seen in isolation from other urban and social phenomena. Links begin to emerge between what at first sight seem to be unrelated social spaces - between, for example, the municipal preservational projects such as the old buildings around Yu Yuen Garden, in the old "Chinese city," now turned into a kind of vernacular mall, and the city's much more publicised developmental projects of cultural modernization, such as the new Shanghai Museum and the Grand Theater, both in an already modernized Renmin Square. We can see hints of a similar logic of globalism operative in each.

Take the new Shanghai Museum, which was opened in 1996. It is designed to resemble a giant ting, an antique Chinese bronze vessel. The obvious visual message here is that in the city's pursuit of modernity, Chinese tradition is not forgotten. But there is also something else. Consider the experience of entering the museum. In the exhibition halls, we find the rare artworks that the museum is famous for expertly displayed: the ancient bronzes, the Sung and Yuan paintings. But what also catches the attention is how ostentatiously clean the museum is, not a common experience in Shanghai. There always seem to be some workers polishing the brass on the railings or the marble on the floor. Even the toilets are kept meticulously clean. The dirtier the streets around it, the cleaner the museum. And suddenly you realize that the museum does not think of itself as being part of a local space at all, but as part of a virtual global cultural network. The Shanghai Museum is not just where artworks are being shown in Shanghai; it is also where Shanghai shows itself off in its museum, with its image cleaned up and in hopes that the world is looking.

But "globalism" is not without its own aporias and anomalies. For example, something of the tensions in Shanghai's new social space can be felt in one admittedly minor but symptomatic example: the etiquette of mobile phones. For the newly affluent entrepreneurial class, these phones are as much functional tools as symbols of the culture of globalism. It is also this class that, along with foreign visitors, can patronize the expensive and elegant restaurants that are reappearing in Shanghai. One of the most expensive of these is the Continental Room at the Garden Hotel, whose standards of elegance require guests to switch off their 
mobile phones out of consideration for fellow diners. What seems an unobjectionable policy from one point of view has produced many a contretemps. For these new entrepreneurs, dining at the Garden Hotel and using mobile phones go together. There is no conception that these electronic devices can be in certain social situations sources of irritation for oneself or others. What we find here is an example of transnationalism without a corresponding transnational subject. These new kinds of social embarrassment may not be insignificant in that they are symptoms of how the speeded-up nature of social and cultural life inevitably results in the production of multiple, sometimes conflicting, paradigms confusing for the person who needs to negotiate them.

Of course, it is true that social life since the modern era has always been marked by change and confusion. Cosmopolitanism has been seen as an ability to acquit oneself, to behave well, under difficult cultural situations by juggling with multiple perspectives - even when these perspectives were forced upon us or adopted in indifference. The question is: Are the kinds of changes taking place in Asian cities and elsewhere today forcing upon us situations in which we cannot behave well, because these changes are threatening to destroy the space of cities as we know them and creating cities we do not know? From this point of view, the apparently slight example of the use of mobile phones in "inappropriate" situations now takes on greater weight. Their indiscriminate use in the present case is neither an example of boorishness nor a lack of consideration for others, nor even a transgression of the boundaries of social etiquette. It is, rather, a genuine confusion about where the boundaries are, making both "transgression" and "behaving well" equally problematic.

If the speed of change is creating spaces we do not understand, then one strategy might be to slow things down - to preserve some almost erased concept of civility and respect for otherness in the midst of chaos. This was what the older cosmopolitanisms had strived for. But, it seems to me, such a conservative strategy has little space for manoeuvre. One of the most interesting things we can learn from the example of urban preservation in Shanghai today is how it, too, is infused with the spirit of globalism. "Preservation" and "heritage" do not act as brakes against development; in some strange way, they further a developmental agenda. The problem of cosmopolitanism today still remains how we are to negotiate the transnational space that global capital produces.

In the corporate sphere, strategies are already in place for negotiating such a space. The key strategy is quite clearly summarised by the notion of arbitrage. In 
its restricted economic sense, arbitrage refers to the way profits are obtained by capitalizing, through the use of electronic technologies, on price differentials in markets situated in different time zones and parts of the world. That is: arbitrage maximises profits by setting up operations in a world of speed and virtuality, and thereby breaking down the traditional boundaries of time and space. The term also refers in a more general sense to the business practices of transnational corporations, including, for example, the export of jobs to countries with the lowest labour costs and fewest labour laws, or spreading the manufacturing process over different parts of the world so that it becomes difficult to assign to manufactured goods a national provenance. These "business practices," it has been well pointed out, constitute a novel kind of politics: "Without a revolution, without even any change in laws or constitutions, an attack has been launched 'in the normal course of business', as it were, upon the material lifeline of modern national societies.... We are thus dealing with politicization through a depoliticization of states." 16

Arbitrage can also be related to the posture now known as glocalization, a portmanteau word blending the "global" and the "local." 17 The term was first used by Japanese businessmen to describe the need to adapt a global outlook to local conditions, a kind of "micromarketing." Glocalization, encapsulated now in the corporate slogan "think globally, act locally," is a top-down approach to society, however: a hybrid term, it concludes by homogenising the hybrid and local. We can read the contemporary value placed by cultural and social critics on hybridity precisely as a protest against homogenisation. Sympathetic though such a position is, it seems to be losing political leverage against approaches like glocalization, which can be seen as a kind of micromanagement of hybridity. Benetton, McDonald's, and Walt Disney all seem to understand this.

Arbitrage may consist of a powerful set of strategies for dealing with the nature of transnational space, but the forms that arbitrage has taken so far give as much cause for concern as for celebration. It is possible to micromanage ourselves to death, as Paul Virilio's work on urbanism and technologies of speed warns. Virilio shows how these technologies - transport, circulation, information - promise or threaten to change in an unprecedented way our experience of space and the city by introducing a new dimension (namely, the global/virtual) that indeed breaks down the limitations of space and time but that also has the

16. Beck, What Is Globalization?, 3-4, 103 (Beck's emphasis).

17. See Roland Robertson, Globalization (London: Sage, 1992), 173-74. See also Robertson, "Glocalizations: Time-Space and Homogeneity-Heterogeneity," in Global Modernities, ed. Mike Featherstone, Scott Lash, and Roland Robertson (London: Sage, 1995), 25-44. 
potential, if we are not careful, to produce a global accident as catastrophic in its own way as Chernobyl:

Beyond the old cosmopolis modelled on ancient Rome, the world-city will surge forth, an omnipolis whose major clinical symptom is the stock exchange system, today computerized and globalized, generating as it does, at more or less constant intervals, a virtual financial bubble which is nothing less than the early-warning signal of the dire emergence of a new kind of accident, an accident no longer local and precisely located in space and time as before, but a general global accident which could well have radio-activity as its emblem. ${ }^{18}$

Is the omnipolis the ominous end of cities as we know them, of space and time as we know them, and of the cosmopolitan?

This specter invoked by Virilio of an unprecedented kind of global accident that implosions in the global system could produce is not apocalyptic prophecy but a provocation to thought. It makes us see that globalism has quietly upped the ante, making a redefinition of cosmopolitanism a matter of great historical urgency. Clearly, cosmopolitanism can no longer be simply a matter of behaving well or even of an openness to otherness. Otherness lost its innocence as a result of the colonial experience. Even less attractive is the alternative of a brutal embrace of ethnocentric vision, an anticosmopolitanism made more extreme because it exists in the new and charged situation of information and speed. Information does not only dispel bigotry but also disseminates it. Can there be a cosmopolitanism for the global age, and what would it be like?

We might look for an answer in the analysis of the nature of cities today, particularly an analysis of their linkage to the transnational more so than to the national. As the fashion designer Yohji Yamamoto said in Wim Wenders's 1989 film Notebook on Cities and Clothes, "I like all big cities. More than Japanese, I feel I'm from Tokyo. . . . Tokyo has no nationality." Large nation-states like the previous Soviet Union have been breaking up, but this is not because some kind of transnational state is coming into being, only a transnational or global space where nation-states are still located. And cities are the locales or nodal points of this transnational space, which exists not in some abstract dimension but in the very specific sites and problem areas of the city. It exists, for example, in the problematic details of heritage and preservation in present-day Shanghai, in the non-places that Augé has pointed to, or in new kinds of social embarrassment that

18. Paul Virilio, Open Sky, trans. Julie Rose (London: Verso, 1997), 83 (Virilio's emphasis). 
are the result of quickly shifting cultural paradigms. Whether a cosmopolitanism for the global age will emerge depends on our ability to grasp a space, that of the global city, that is always concrete even in its elusiveness. And this involves not so much imagining a transnational state as reimagining the city.

In a similar vein, the cosmopolitan today will include not only the privileged transnational, at home in different places and cultures, as an Olympian arbiter of value. Such a figure, it could be argued, has too many imperialistic associations. The cosmopolitan today will have to include at least some of the less privileged men and women placed or displaced in the transnational space of the city and who are trying to make sense of its spatial and temporal contradictions: the cosmopolitan not as a universalist arbiter of value, but as an arbitrageur/ arbitrageuse.

This is arbitrage with a difference. It does not mean the use of technologies to maximise profits in a global world but refers to everyday strategies for negotiating the disequilibria and dislocations that globalism has created. Arbitrage in this sense does not allude to the exploitation of small temporal differences but refers to the larger historical lessons that can be drawn from our experiences of the city. This is where the de-scriptions of Shanghai and Hong Kong, to return to these cities one last time, can contribute to a rethinking of the cosmopolitan today. In Shanghai, negotiating the anomalies of extraterritoriality so that a kind of grace comes out of the grotesque; and in Hong Kong, the development of a culture of disappearance under conditions of dependency - these were already examples of cultural arbitrage. As for Borges, a more ambiguous relationship exists between him and the figure of the arbitrageur. To embrace "universal values" in Buenos Aires as Borges did was to be trapped to some extent in the imperialist game. Where Borges showed himself to be a supreme arbitrageur was in the other games he chose to play: the games with time and infinity, with language, and with the space of the labyrinthine city.

Whether arbitrage reworked as cultural strategy can counter Virilio's dire warnings remains an open question. But it is cosmopolitanism's best chance. Cosmopolitanism has always been a way of being in the world, however confusing the world is, and nothing so far is as confusing as globalism. Cultural arbitrage may be a way of creating a global culture worthy of the name.

Ackbar Abbas is head of comparative literature and codirector of the Center for the Study of Globalisation and Cultures at the University of Hong Kong. His recent publications include Hong Kong: Culture and the Politics of Disappearance (1997) and "Dialectic of Deception" (Public Culture, spring 1999). 